\title{
Deliberación y conflicto en tiempos de hacer la paz: análisis de las protestas populares (2012-2015) en Colombia desde el constitucionalismo democrático-popular *
}

\author{
Recibido: 02 de octubre del 2018 • Aprobado: 09 de noviembre del 2018 \\ https://doi.org/10.22395/ojum.v17n35a6 \\ Andrés Felipe Roncancio Bedoya**
}

\begin{abstract}
RESUMEN
El presente artículo plantea que a partir de las protestas populares que se desarrollaron entre el 2012 y 2015 en Colombia, se puede hacer una lectura sobre qué espera la ciudadanía de la implementación del Acuerdo de Paz al estudiar las exigencias que se generan debido a la insatisfacción general frente al papel del Estado y su incumplimiento con lo que se encuentra positivizado en la constitución. Así, se plantea una revisión a la concepción de la ciudadanía y cómo esta espera respuestas más allá de las condiciones de justiciabilidad dadas institucionalmente, lo que impulsa la creación de nuevos escenarios de deliberación que se rastrean teóricamente en una lectura de la Constitución Política, y que pretende devolver la constitución al pueblo. El análisis de esas exigencias y/o necesidades permite evidenciar la relevancia del acuerdo de paz y la apuesta en la agenda de gobierno alrededor de la identificación de las protestas y su relación con los derechos sociales, económicos, culturales y ambientales que deben estimar cómo interviene el gobierno y cómo este fija el cumplimiento de su política social.
\end{abstract}

Palabras clave: ciudadanía; paz; protestas populares; constitucionalismo democrático; derechos sociales.

Artículo de investigación derivado del proyecto "Protestas populares y democracia 2011-2016" auspiciado por la VIII convocatoria de investigación de la Institución Universitaria de Envigado.

** Abogado, Institución Universitaria de Envigado, Envigado, Colombia. Magíster en Derecho con énfasis en Derecho Público, Universidad de Medellín, Medellín, Colombia. Candidato a Doctor en Derecho con énfasis en Estructura y Funcionamiento del Estado, Universidad de Medellín. Profesor investigador de la Institución Universitaria de Envigado, Envigado, Colombia. Correo electrónico: afroncancio@correo.iue.edu.co Orcid: https://orcid.org/0000-0002-1257-3813 


\title{
Deliberation and Conflict in the Times of Peace Building: An Analysis of Popular Protests (2012-2015) in Colombia from a Democratic-Popular Constitutionalism Approach
}

\begin{abstract}
The present paper proposes that, taking in account the popular protests that took place between 2012 and 2015 in Colombia, it is possible to make a reading about what citizens expect from the Peace Agreement implementation when studying the demands generated due to general dissatisfaction with the role of the State and its failure to comply with what is found positive in the constitution. A revision of the conception of citizenship is proposed, also about how it expects answers that may even go beyond the institutionalized conditions of justiciability. The latter drives to the creation of new deliberation scenarios theoretically based in a reading of the Political Constitution, which aims to return the constitution to the people. The analysis of these demands and / or needs makes it possible to evidence the relevance of the peace agreement and of the government's agenda commitment with the identification of the protests and their relationship with social, economic, cultural and environmental rights - which must estimate how must the government intervene and how determine how to fulfill its social policy.
\end{abstract}

Keywords: citizenship; peace; popular protests; democratic constitutionalism; social rights.

\section{Deliberação e conflito em tempos de paz: análise dos protestos populares (2012-2015) na Colômbia a partir do constitucionalismo democrático-popular}

\section{RESUMO}

O presente artigo propõe que, a partir dos protestos populares que ocorreram entre 2012 e 2015 na Colômbia, pode-se realizar uma leitura sobre o que a cidadania espera da implementação do Acordo de Paz ao estudar as exigências geradas devido à insatisfação geral diante do papel do Estado e seu incumprimento com o que se encontra positivizado na constituição. Assim, apresenta-se uma revisão da concepção de cidadania e como esta espera respostas mais além das condições de justiciabilidade dadas institucionalmente, o que impulsiona a criação de novos cenários de deliberação que são teoricamente rastreados em uma leitura da Constituição Política e que pretende devolver a constituição ao povo. A análise dessas exigências e/ou necessidades permite evidenciar a relevância do acordo de paz e a aposta na agenda de governo acerca da identificação dos protestos e sua relação com os direitos sociais, econômicos, culturais e ambientais que devem estimar como o governo intervém e como fixa o cumprimento de sua política social.

Palavras-chave: cidadania; paz; protestos populares; constitucionalismo democrático; direitos sociais. 


\section{INTRODUCCIÓN}

A partir de la firma y suscripción del Acuerdo de Paz entre las FARC-EP y el Estado colombiano, y con base en estudios sobre el conflicto interno armado y derechos fundamentales (Roncancio, 2013; Roncancio y Londoño, 2015; Roncancio, Moreno y Hurtado, 2016; Restrepo-Yepes et al., 2017; Tobón y Mendieta, 2017; Moreno, Roncancio, Lopera y Carvajal, 2018; Castro, Vélez y Madrigal, 2018; Roncancio, Hurtado y Vargas, 2018; Pabón, Bustamante y Toro, 2017), se hace necesario determinar los lineamientos que se consideran relevantes al momento de plantear una discusión acerca de los retos y desafíos que tiene Colombia, más allá de establecer las obligaciones jurídicas que se desprenden de los acuerdos fijados entre las partes en el proceso de paz. Entre estos, se encuentra la imperiosa tarea de establecer la manera en la que lo pactado en la mesa de negociación tiene que estar sujeto, en una primera instancia, al cumplimiento de los pactos realizados entre las partes, como punto de encuentro y reconciliación en acciones que permitan superar el conflicto; y en una segunda instancia, al reconocimiento del contexto político y social desde la perspectiva de la sociedad civil, en cuanto esta genera reclamos al Estado en materia de derechos fundamentales.

Por esta razón, determinar qué se debe entender por posconflicto o posacuerdo no puede suponer una caracterización formal en la que el reconocimiento de la ciudadanía, como un actor más del conflicto, sea considerada de forma implícita, en la medida en que las acciones y obligaciones pactadas contemplan una intervención que involucra a la sociedad civil. Al contrario y en un sentido amplio, se espera que de las negociaciones surjan respuestas a los reclamos, exigencias y necesidades que Colombia reconoce en términos de derechos fundamentales.

Bajo dicho panorama, se propone que la consecuencia directa del Acuerdo de Paz tendrá valor para la sociedad si desde el mismo se hace un reconocimiento a la ciudadanía minoritaria que, a partir de protestas sociales ha generado demandas sobre derechos fundamentales al Estado, las cuales, pese a su naturaleza minoritaria, tienen igual valor por la cláusula social del Estado colombiano que se auto-reconoce como pluralista y como norma de normas (Roncancio, H. y Roncancio, A., 2014; Moreno, Roncancio, Restrepo y Carvajal, 2017).

Así, el presente artículo tiene como propósito identificar en qué condiciones estos sectores ciudadanos minoritarios hacen parte fundamental del propósito de paz emprendido por el Estado colombiano, que proponen una racionalidad de gobierno deliberativo y por lo tanto, una lectura democrática de la Constitución Política. Lo anterior puesto que dialogar acerca de la finalización del conflicto entre las FARC-EP y el Estado colombiano debe tener una lectura constitucional de las protestas populares que se vivenciaron en el país en medio de las negociaciones de la Habana. Se reconoce que estas protestas populares son de vital importancia para la construcción de paz. 
En la medida en que son representaciones materiales de la situación contextual de los déficits existentes en materia de derechos fundamentales, posicionan el debate sobre cómo materializar los derechos que se encuentran consagrados constitucionalmente, y desde allí plantear cómo se puede reconstruir el tejido colectivo vulnerado a causa del conflicto armado interno. Con esto en mente, se propone identificar cuáles son los elementos más relevantes para la agenda pública nacional, sin dejar de lado el reconocimiento de que todas las ramas del poder público son corresponsables de la efectivización de los derechos fundamentales.

\section{DE LA PROTESTA POPULAR A LA CIUDADANÍA DELIBERATIVA: UNA REVISIÓN DEL CONSTITUCIONALISMO POPULAR AL CONSTITUCIONALISMO DEMOCRÁTICO}

Indudablemente, una de las cuestiones más relevantes a las que se ve enfrentado el constitucionalismo parte de la pregunta: ¿cómo se legitima un Estado constitucional?, y de forma coherente, ¿cómo dicho Estado interviene los problemas y las exigencias que se presentan en cada uno de los contextos? Estos interrogantes plantean -desde la perspectiva política- una cuestión fundamental que se responde a través de las acciones que emprende el Estado para garantizar los derechos fundamentales, los cuales, más allá de los términos normativos que definen cada derecho fundamental, presuponen acciones materiales que dan cuenta de su cumplimiento. En estos casos, los veedores son directamente los ciudadanos, que son los actores que disfrutan de estos derechos y cuestionan su incumplimiento. Así, es la ciudadanía la que a través de la democracia, orienta de forma mayoritaria lo que se debe visibilizar y priorizar en la agenda pública (Przeworski, 2010).

Así las cosas, esta conceptualización parte por reconocer, como lo propone la profesora Ferrer (2017), el modelo y el concepto de ciudadanía que se ha transformado con la visión del Estado y su consagración constitucional, pues tiene un punto de partida en el mismo concepto de democracia representativa que surgió a finales del s. XVIII en Francia, con el Estado Liberal de Derecho y el reconocimiento de derechos individuales a los ciudadanos. Posteriormente se da el paso al modelo republicano de ciudadanía propio de democracias participativas, tal como el Estado que emerge de la independencia norteamericana. De forma subsiguiente, el modelo comunitarista bajo el cual el ciudadano tiene el deber de servir a la comunidad a la que pertenece, gracias a la sujeción de los derechos como contrapuesta de la adhesión al contrato social, estando esta inclusive por encima de sus libertades. Se arriba entonces a la visión de ciudadanía diferenciada, que conlleva un reconocimiento en dos sentidos en la medida en que: i) establece las concesiones en materia de derechos fundamentales que se reconocen y se declaran como aquello que se le puede exigir al Estado: y ii) determina una carga de deberes objetivos que construyen la esfera pública, y por ello, una categoría de 
corresponsabilidad frente a los derechos fundamentales de los demás, en tanto la defensa de estos supone implícitamente, la defensa de los propios derechos.

En este sentido, el término "ciudadanía" se puede leer a través de varios modelos construidos a lo largo de la historia y que reflejan implícitamente, distintas formas de democracia. Entre estos, se considera que el modelo de ciudadanía diferencial es de vital importancia en la medida que determina como reto fundamental del ciudadano, la implacable demanda de las insatisfacciones sociales económicas, políticas, cultures e incluso éticas, que deben pasar a la agenda de la razón pública del Estado en cuanto se explican como la razón misma de este (Santos, 2003).

Es así que la concepción de ciudadanía diferencial tiene un nuevo valor representativo cuando se le considera en un Estado Social de Derecho, puesto que, bajo la tesis de intervención, se le interpreta conforme al pro homine, lo que comporta que el Estado debe garantizar la supervivencia, dignidad humana y autarquía del derecho de los derechos fundamentales (Restrepo, 2018). Allí, la democracia mayoritaria encuentra un límite de naturaleza formal y torna participativa y pluralista, reconoce diferentes ciudadanos a los que considera como grupos, los cuales a causa de una condición minoritaria, están en desventaja con respecto al resto de la sociedad. Dicha desventaja crea dentro de la agenda pública la necesidad de desarrollar los principios constitucionales de igualdad y por tanto, de discriminación positiva. Como resultado de la cláusula social del Estado, se consagra una dimensión de ciudadanía multicultural que se desarrolla con base en la multinacionalidad y polietnicidad, coherente al modelo de ciudadanía posnacional desarrollado por Habermas (1994), y su patriotismo constitucional propone una ciudadanía sin distinciones (Ferrer, 2017).

Así, esta tesis plantea, como lo proponen Young (2002) y Kymlicka (1995), que la toma de decisiones del Estado debe considerar a todos los actores posibles dentro del Estado, así los márgenes de inclusión dentro de los que el ciudadano es considerado como sujeto político, como ser humano y como asunto de gobierno - en la medida que cada necesidad colectiva o individual es un asunto para resolver por el Estado- se amplían. Más allá de una diferenciación teorética, esta discusión trae la consideración de si la ciudadanía es una conformación frente a la relación del Estado y la constitución, se da cuenta entonces de que la visión de ciudadanía se puede conceptualizar como ciudadanía política. En este aspecto, el proceso colombiano ha sido reconocido en los tribunales, especialmente en sede constitucional, como lo propone Ferrer (2017) citándose a sí misma, en los siguientes términos:

La ciudadanía política, se puede
simplificar en la frase común,
derechos a elegir y ser elegidos/
as, su institución, los parlamentos
y cargos de elección popular de
las municipalidades; la ciuda-
danía social, garantizadora del 
bienestar económico, del derecho a participar del patrimonio social y vivir una vida conforme a los estándares corrientes de la sociedad, la institución bandera, el sistema educativo y los servicios sociales; y finalmente la ciudadanía civil, necesaria para el reconocimiento y desarrollo de las libertades básicas del individuo, incluye todas las libertades, el derecho de propiedad, a celebrar contratos y obviamente el acceso a la justicia en defensa de estos derechos, la institución clave para esta ciudadanía son precisamente los tribunales de justicia (Ferrer, 2010, p. 115).

De esto se desprende que la cuestión a resolver es si de forma restrictiva corresponde a los tribunales de justicia afrontar la cuestión propia de la conceptualización de los derechos fundamentales, puesto que, si bien históricamente en el contexto colombiano estos se han encargado de realizar la tarea de justiciabilizar al respecto, las prácticas sociales ponen en la palestra pública la necesidad de generar otros espacios; no porque estos no cumplan a cabalidad la tarea de desarrollar las condiciones propias de un Estado constitucional, sino porque bajo los términos de la escena política, las manifestaciones populares han tomado relevancia dentro de la razón pública del Estado. Lo anterior indica que, más que reducir el planteamiento de la obtención de derechos fundamentales bajo el supuesto de que existen las acciones judiciales para hacer efectivo el derecho, es preciso que todas las ramas del poder público sean garantes de los reclamos de la ciudadanía.
Bajo ese criterio, se plantea como necesaria la relación directa entre la protesta social y los derechos constitucionales, y se puede identificar que, antes de ser concesiones positivizadas, existe un escenario político, mas no jurídico, en el cual se discuten los derechos fundamentales que se convierten en objetos democráticos que no pasan por el racero del institucionalismo. Sin embargo, como su vocación está dirigida a defender los derechos fundamentales, precisan llegar a un nivel de efectivización que no se pueden limitar a acciones de carácter judicial, puesto que se pueden convertir en concesiones a través de otras manifestaciones jurídicas (Restrepo, 2018).

Por esta razón, se puede afirmar que entender la ciudadanía plantea, de forma directa, comprender que la Constitución no tiene, de forma restrictiva, una dimensión jurídica, sino que la Carta Política en sí misma, comparte una naturaleza eminentemente política en la que la democracia determina espacios de visibilización que asimismo, crean escenarios de deliberación que vivifican las condiciones del ciudadano constitucional por fuera de esos espacios institucionalizados para participar; esto da cuenta de que a pesar de ser minorías, suponen la necesidad y obligación de intervención del Estado, que tiene dicho compromiso en la Constitución como texto jurídico.

Desde esta concepción, es plausible afirmar que, a mayor participación, mayores niveles de democracia y por lo tanto mayores niveles de poder para la ciuda- 
danía (Serna, 2008). Por consiguiente, la tarea de la ciudadanía es abiertamente democrática y solo es democrática una ciudadanía en tanto entiende que los derechos fundamentales son un objeto por conquistar en todo espacio público y en toda esfera pública, por lo cual la democracia debe ser deliberativa, lo que permite una relación entre las mayorías y las minorías. De allí que la propuesta de Habermas, revestida de postulados kantianos, representa el reconocimiento de la democracia en el ser humano, con su teoría de la acción comunicativa, que consiste en acciones que tienen por fin el entendimiento intersubjetivo que se lleva a cabo en una situación contextual de habla. Allí se evidencia la influencia del imperativo categórico de Kant, desde el cual desarrolla su principio ético discursivo, por el que una norma es válida si se adapta al criterio de razón universal. Así pues, la ambiciosa propuesta habermasiana de fundamentar una ética del discurso implica reconstruir la ética kantiana desde los presupuestos de su teoría de la acción comunicativa (Duque, 2014), lo cual políticamente representa reconocer la necesidad de dar importancia a todos los interlocutores y de determinar como asunto de la agenda pública toda necesidad, por mínima que sea, considerada en razón de los intereses de la mayoría.

En suma, la teoría habermasiana plantea que toda cuestión moral puede remitirse a cuestiones prácticas que pueden decidirse por medio de razones, o a conflictos de intereses que pueden solventarse a través del alcance de un determinado consenso. Para el autor, los asuntos de carácter moral serán todos aquellos que puedan elaborarse desde el punto de vista kantiano de la universalización, pensada ahora en términos intersubjetivos. Para tales efectos, Habermas define la idea de punto de vista moral, desde el cual quien se expresa está suponiendo que propone algo universalmente válido. Es esta una concepción formalista, procedimental, cognitivista y universalista de la ética, que no se basará tanto en la razón práctica kantiana (en nuestra conciencia moral) sino en los presupuestos pragmáticos de la comunicación. (Duque, 2014, p. 8).

Esta discusión trae consigo la necesaria interrogante sobre si entonces esta visión implica que la deliberación deba pasar a un escenario de radicalización, en tanto que, si el problema en la vista política es de orden comunicacional, las minorías y quienes se encuentran excluidos por su condición deben plantear la necesidad de generar apropiación de la esfera pública mediante una manifestación directa. Esta puede ser de movilización social, visibilización social o participación contra mayoritaria, y las mayorías se sujetarían a dialogar sobre las dinámicas que impone la constitución.

En este orden de ideas, se determina que la disposición de la democracia en términos representativos se queda corta por su visión funcionalista de lo mayoritario. Y como en el plano constitucional las minorías y sus derechos se convierten en limitaciones al poder de las mayorías, se 
manifiesta la relevancia de la apuesta de la democracia deliberativa, la cual persigue que los ciudadanos conformen un diálogo en pos de consensos que puedan tornar de obligatorio cumplimiento y que exijan así el compromiso de los ciudadanos a integrar el debate público, así como a respetar la pluralidad (Baños, 2006).

Finalmente, la deliberación se convierte en un elemento necesario de inclusión, esto con miras a que la deliberación se arraiga en el consenso, aún por encima del conflicto que se genera de forma natural en sociedades pluralistas y libres, además del desconocimiento de ciertos grupos minoritarios en situación de vulnerabilidad que buscan la incorporación de sus demandas ciudadanas en el debate público. Así, la democracia radical persigue de igual forma, la inclusión de las diferencias y proteger a los más débiles del conjunto social.

Por lo anterior, la búsqueda de una democracia deliberativa como alternativa a la crisis de la democracia liberal que se empezó a mostrar insuficiente, parte de tratar de alcanzar consensos entre los ciudadanos libres e iguales, dispuestos a realizar un intercambio de puntos de vista con argumentos fundamentados en la razón -lo que los dota de un carácter universal-, y que producto de esta deliberación se decida lo público en aras de lograr el bien común. Dicho consenso torna en un mero ideal para la democracia radical toda vez que lo político, en especial en las sociedades de finales del siglo $\mathrm{XX}$, se vuelve completamente variado y conflictivo. Del mismo modo, dicho ideal liberal y la universalidad de lo ético recibe fuertes ataques bajo el modelo de democracia (Vidiella, 2013).

Los presupuestos alrededor de la democracia sientan la base epistemológica del constitucionalismo popular, el cual se presenta como una corriente de pensamiento o cuerpo de literatura jurídico que parte de "la premisa según la cual el gobierno le pertenece al pueblo (antes que a sus representantes y mucho antes que a la justicia)" (Gargarella, 2007, p. 1). Esto pone de manifiesto que incluso los jueces constitucionales no son los únicos ni los mejores intérpretes de la Constitución política de un Estado, que el ciudadano integrante de ese Estado tiene como derecho, muchas veces no reclamado, no solo interpretar la Constitución sino también rechazar la interpretación hecha por el tribunal constitucional o incluso reformarla. En palabras de Roberto Niembro:

En términos generales el constitucionalismo popular se caracteriza por enfrentarse a la supremacía judicial y a la visión elitista según la cual los jueces son mejores intérpretes constitucionales, aunque no todos los populares necesariamente son "anti-Corte" o "anti-control judicial". El punto clave es la limitación de la supremacía judicial y la elaboración de la doctrina constitucional como una agencia colectiva, cuyo protagonista es el pueblo. Es popular, nos dice Tushnet, porque distribuye ampliamente 
la responsabilidad sobre la Constitución y refuerza el papel de la gente en su interpretación. En palabras de Kramer: "El papel del pueblo no está limitado a actos ocasionales de creación constitucional, sino a un control activo y continuo sobre la interpretación e implementación de la Constitución, sin que el Tribunal Supremo pueda monopolizar la interpretación de la misma". No basta, dice el profesor de Stanford, con que el pueblo pueda crear derecho constitucional a través del proceso de reforma, sino de reivindicar su papel como intérprete constitucional. (Niembro, 2013, pp. 195-196)

A este tenor, Kramer (2004) sostiene que el constitucionalismo popular ha predominado a lo largo de la mayor parte de la historia estadounidense, pero que desde la década de 1980 la supremacía judicial parece "haberse convertido en la norma", adoptado tanto por la izquierda como por la derecha debido a "actitudes profundamente antidemocráticas" que subyacen a cada una de ellas. Kramer (2004) considera a los "partidarios actuales de la supremacía judicial" como los "aristócratas contemporáneos", que encarnan un tipo de traída de vuela del "Alto Federalismo" que desestima "las políticas democráticas como si infundieran miedo y fueran amenazantes" y que conserva "dudas profundamente arraigadas sobre los ciudadanos del común" (Post y Siegel, 2017).

En este sentido, el constitucionalismo popular está basado - como ya se ha mencionado- en la visión del ciudadano como una parte integral y fundamental del aparato político y judicial de un Estado, en el cual el ciudadano no puede simplemente ser un sujeto pasivo que acepta las decisiones e interpretaciones de la constitución que hacen los jueces y en especial, el tribunal constitucional supremo - que para el caso de Colombia sería la Corte Constitucional y para el caso estadounidense sería la Corte Suprema de Justicia-, sino que también rechaza la postura de aceptar la interpretación hecha por dichos organismos como decisión definitiva e inapelable; es decir que la concepción de un tribunal especial como tribunal de cierre de las discusiones constitucionales estaría revaluada para este sistema.

De esta forma, es claro que para el constitucionalismo popular las tres ramas clásicas del poder público: poder ejecutivo, poder legislativo y poder judicial no pueden estar por encima del pueblo, este debe ser considerado como una cuarta rama, incluso encumbrada sobre las demás y especialmente sobre la rama judicial, ya que no puede entenderse cómo la constitución, que en términos rousseaunianos sería el pacto social, pueda ser interpretada por un tribunal especial, pero no por el pueblo. En palabras de Diana Durán-Smela:

La premisa principal [...] es que para el constitucionalismo popular el gobierno y el control constitucional le pertenecen al pueblo, antes que a sus representantes o al poder judicial. Por lo tanto, esta teoría cuestiona fuertemente la idea de que la 
Corte Suprema norteamericana y sus jueces sean los únicos y exclusivos intérpretes de la Constitución Política. Para el ordenamiento norteamericano y para el colombiano también, son los tribunales constitucionales los que deben determinar el alcance y el contenido del texto constitucional, y ello no solo frente a las otras ramas del poder público, sino frente a los ciudadanos en general. (Durán, 2011)

Este papel activo del ciudadano y la no supremacía de ninguna rama del poder público sobre otra genera como consecuencia la concepción de la interpretación extrajudicial que implica que tanto el ciudadano común, como otras ramas del poder público pueden hacer interpretación constitucional. Allí se debe evaluar ese distanciamiento del ciudadano del común con el derecho y la constitución, es decir, el ciudadano no solo desconoce las leyes, sino que no tiene ninguna relación con el derecho, y esta brecha genera que el ciudadano no se apropie y no acate las normas ni las decisiones judiciales. Se podría inferir de esta manera que una de las razones para desacatar el derecho tiene que ver precisamente con esta visión, ya que al no conocer la norma y no conocer las decisiones judiciales, indefectiblemente se genera la inobservancia del derecho y si a eso se le agregan elementos como la presunción de derecho de que la ignorancia de la ley no sirve de excusa, pues se está en presencia del caldo de cultivo perfecto para los conflictos sociales, así lo refieren Alterio y Niembro:
Este tipo de problemas de disociación entre derecho y comunidad, no sólo [sic] existen en América Latina, sino que encuentran en la región una relevancia muy particular. Ello es así, al menos por dos razones. En primer lugar, porque en América Latina, a diferencia de lo que ocurre en los Estados Unidos, el derecho (y muy en particular las decisiones de nuestros tribunales superiores) no es objeto de un continuo escrutinio público, sobre todo a través de la prensa masiva y medios especializados. El hecho de que medios y universidades utilicen los fallos judiciales como objeto cotidiano de análisis, hace que en los Estados Unidos el derecho quede sujeto a mejores controles. Algo que, en última instancia, permite tejer lazos entre derecho y comunidad, una situación que lamentablemente es mucho menos habitual en América Latina.

La segunda razón que muestra por qué los problemas en cuestión son particularmente relevantes para Latinoamérica, tiene que ver con la desigualdad extrema que padece la región en todas sus esferas. Dicha desigualdad tiende a traducirse en un derecho también desigual y, podríamos agregar, cada vez más desigual. En la región, más que en otros contextos, la creación, interpretación y aplicación del derecho tiende a quedar en manos de élites, normalmente desvinculadas de los intereses y necesidades de la colectividad. El resultado de todo ello es un derecho producido por un puñado de la sociedad, en beneficio propio, aunque ejercido a nombre de todos los miembros de la comunidad (Alterio y Niembro, 2018). 
Por ello, el valor categórico no implica sujetar la condición constitucional al poder popular, pero sí condiciona la importancia de poner en la agenda constitucional las exigencias que realiza el pueblo. Por ende, la tarea plantea la construcción de una ciudadanía crítica, formada e integrada a la discusión constitucional. Así, esta tesis permite reafirmar la importancia de la deliberación y de la propuesta del constitucionalismo democrático.

Esta visión del constitucionalismo democrático (Post y Siegel, 2017) pretende generar consenso entre las distintas interpretaciones constitucionales en sociedades heterogéneas, para que la interpretación lógica y racional fundamentada en la ley que realicen los profesionales del derecho como los jueces, se armonice con la interpretación constitucional del pueblo. No ha de centrarse en los métodos de interpretación que a su modo de ver no resuelven la querella, no interesa cómo los juristas llegan a sus conclusiones sino el desacuerdo que puede suscitar y cómo conciliar las cortes judiciales con la ciudadanía. Esto se distancia del constitu cionalismo popular puesto que sin extraer la hermenéutica constitucional del poder judicial para devolver la constitución al pueblo como propone este, busca que los tribunales revistan sus decisiones de una mayor legitimidad al no desconocer la manifestación popular. Una alternativa válida al constitucionalismo popular bien podría ser la que plantean Post y Siegel:

Proponemos un modelo para entender los esfuerzos estatales por hacer cumplir la Constitución en condiciones de controversia pública. Llamamos a este modelo el "constitucionalismo democrático". El constitucionalismo democrático reafirma el rol del gobierno representativo y la ciudadanía que se moviliza en la tarea de hacer cumplir la Constitución, al tiempo que reafirma el rol de las cortes que usan la razón legal para interpretar la constitución. A diferencia del constitucionalismo popular, el constitucionalismo democrático no busca evitar que la constitución resida en las cortes. El constitucionalismo democrático reconoce el rol esencial de la aplicación judicial de los derechos constitucionales en la comunidad política estadounidense. A diferencia de un enfoque jurídico sobre las cortes, el constitucionalismo democrático aprecia el rol esencial que la participación pública juega al guiar y legitimar las instituciones y las prácticas de revisión judicial. Los juicios constitucionales basados en la razón legal profesionalizada pueden adquirir legitimidad democrática sólo [... s] si esa razón profesionalizada se funda en valores e ideales populares. El constitucionalismo democrático observa que la adjudicación está incrustada en un orden constitucional que regularmente invita al intercambio entre funcionarios y ciudadanos alrededor de preguntas de significado constitucional (Post y Siegel, 2017, p. 9).

El constitucionalismo democrático persigue que la justicia constitucional no sea extraída de los tribunales constitucionales, ni que se elimine la interpretación profesional y técnica del derecho por par- 
te de los magistrados, sino que los fallos proferidos se vean acompañados por las ideas sobre materia de la Ley Fundamental que presentan distintos sectores o movimientos de la ciudadanía y de quienes se encuentran revestidos de legitimidad democrática, como son los representantes políticos. Persigue que los conflictos, visibles en las movilizaciones sociales a causa del desacuerdo con un fallo constitucional, se concilien con lo que dicen las cortes. En palabras de Malagón:

La propuesta del Constitucionalismo Democrático gira en torno a la defensa del activismo judicial y progresismo que se evidencia a través de los diferentes pronunciamientos de los Tribunales Constitucionales, buscando la participación activa de actores civiles y políticos, así como de funcionarios y correcta coordinación de las ramas del poder público; sin embargo al interior de la propuesta democrática existen corrientes que se alejan en mayor o menor medida de la propuesta general y exponen otras características o elementos a dicha propuesta, pero sin desconocer la función del juez constitucional como intérprete de la Carta Política e inclusive como agente de cambio social (Malagón, 2014, p. 11).

En esta orientación la interpretación constitucional surge de la interacción de las diferentes ramas del poder público, así como de asociaciones civiles, partidos políticos, movimientos sociales, opinión pública, centros de investigación y el poder judicial. Es decir que esta corriente propone una interacción de la sociedad en general con el poder judicial, para así garantizar, no la correcta interpretación de la constitución, sino también la aceptación de dicha decisión por parte de los ciudadanos y demás ramas del poder público, y con esto evitar los llamados choques de trenes, pues la decisión parte del consenso general. Robert Post y Reva Siegel en su libro Constitucionalismo democrático, por una reconciliación entre Constitución y pueblo, lo expresan así:

El constitucionalismo democrático se afirma como una concepción sobre la capacidad que deben tener los tribunales superiores para reflejar e incorporar en sus fallos las perspectivas constitucionales de diversos sectores y organismos democráticos, con el objetivo de configurar de manera conjunta el significado del derecho, a través de un diálogo constructivo. En definitiva, a esta corriente no sólo [...] le interesa cuestionar que los tribunales se hayan atribuido ciertas facultades que originalmente no les fueron conferidas: le interesa también proponer una nueva forma de activismo judicial, que sea sobre todo consciente de que el significado de la constitución se establece a partir de interacciones fluidas y constantes con las otras ramas del poder público, las asociaciones civiles, los partidos políticos, los movimientos sociales, la opinión pública, los centros de investigación y el poder judicial en su conjunto. Según este enfoque, la ley no puede emanar de un intercambio exclusivo entre magistrados. (2013) 
En esta dimensión se encuentra valor a la expresión de representación democrática, en cuanto entiende la importancia de la protesta popular y la incorpora, no como una apuesta sobre la visión de la expresión política que deba ser vinculada, sino como una inmediación necesaria de deliberación sobre la dinamización del Estado y la constitución en sí misma.

\section{METODOLOGÍA}

Para efectos de este artículo, se plantea determinar cómo desde el reconocimiento teórico planteado a partir de la construcción del estado del arte, se reconocen las dimensiones claras con las cuales el concepto de ciudadanía lleva implícita una visión que debe revisar el constitucionalismo a partir de la propuesta deliberativa, en la que la conceptualización del ciudadano hoy plantea una discusión por fuera del institucionalismo y lo cual se genera a partir de un circulo hermenéutico (Dueñas, 2011) que origina, a partir de variables, la relación de los datos a analizar. Para ello, se seleccionó el lapso de 2012 a 2015 para analizar las protestas que se generaron y las cuales se recolectaron mediante la revisión documental de periódicos y prensa. La ubicación temporal del estudio parte de establecer como unidad de análisis el momento en el cual se desarrolló la etapa más álgida de las negociaciones de paz en la Habana, entre el Gobierno Nacional y las FARC-EP, con la finalidad de determinar cómo, a la par del proceso institucional, el Estado colombiano afrontó problemáticas que se pueden leer en materia de derechos fundamentales, con la condición de aplicar las categorías de análisis construidas para la discusión.

En ese sentido y a partir de las condiciones mencionadas, el rastreo historiográfico no pretende generar análisis estructurados sobre las manifestaciones populares o protesta social, sino que busca construir una caracterización de las mismas a partir de una rúbrica que en un primer momento consagra las siguientes categorías:

Tabla 1. Variables de análisis de cada una de las protestas

\begin{tabular}{ccc} 
Fecha Protesta & $\begin{array}{c}\text { Alcance } \\
\text { tores } \\
\text { geográ- } \\
\text { fico }\end{array}$ & $\begin{array}{c}\text { Reper- Demanda Duración } \\
\text { torio }\end{array}$ \\
\hline
\end{tabular}

Fuente: elaboración propia

Con lo anterior se pretende dar cuenta de cuáles son los límites que se consideran propios de los Acuerdos de Paz de la Habana, determinar si estos tienen un margen de desarrollo dentro del Acuerdo final y en razón de qué derechos fundamentales se deben identificar las necesidades inminentes, bajo el entendimiento de la relación funcional existente con dicho acuerdo. Con ello, se busca sostener que la discusión sobre la paz y su construcción no pasa solamente por el lineamiento de la implementación formal, sino también por la efectivización de otros derechos fundamentales que se deben plantear dentro de la agenda pública de cada una de las ramas del poder público, para encontrar que la 
justiciabilidad de los derechos parta de los diálogos del Estado con la ciudadanía.

Finalmente, con dicha información se determina el espectro de derechos fundamentales que se establecen como prioritarios dentro de la agenda pública nacional y cómo se les puede establecer como de vital relevancia para la construcción de una paz "estable y duradera".

\section{ANÁLISIS Y DISCUSIÓN}

La protesta social es un derecho constitucional consagrado en el artículo 38 de la Constitución Política, su valor intrínseco no está dado porque reglamenta la posibilidad de asociarse y levantar reclamos de forma colectiva, su valor es simbólico y eminentemente político, puesto que a través del ejercicio de la protesta se manifiesta la dimensión contra-mayoritaria implícita dentro de la cláusula social. En esta, el posicionamiento de los tradicionalmente excluidos (Santos, 2003) no pasa por ser una medida de discriminación positiva, se observa así una negación condicionada al poder judicial o al reconocimiento minoritario, sino que se posiciona como un reclamo efectivo de una agenda política en materia de derechos fundamentales. En este sentido, la Constitución se construye como un límite formal y las protestas populares se consolidan como los espacios a discutir desde el plano político de los derechos fundamentales.

Con esto se tiene que sociedades democráticas basadas en el pluralismo jurídico tengan como base fundamental la dignidad humana como criterio de racionalidad y como parte de su contrato social. Dicha consideración torna fundamental en la medida en que se crea una relación de correspondencia entre las mayorías y las minorías, las cuales generan así la condición de crear derechos subjetivos sobre aquellos derechos que se encuentran positivizados dentro del Estado, como lo propone el profesor Rodolfo Arango (2001).

La discusión alrededor de la concesión de derechos fundamentales que se delimita cuando se les analiza a través de la protesta popular, permite identificar que el reconocimiento constitucional resulta mediado en correspondencia con la justicia, planteada a partir del liberalismo corregido de Rawls (2004). Esto al definir el concepto de razón pública como mediadora de la institucionalidad al determinar la fijación de condiciones igualitarias para todos, pero cuyas condiciones se basan en la necesidad de generar fórmulas de equidad y equiparación de los desiguales, lo cual es conforme a lo analizado por el profesor Restrepo (2012, p. 63):
[...] la Razón Pública orienta la toma de decisiones esenciales para el funcionamiento político de una sociedad democrática, que obliga a todos por igual, que es vinculante porque es una construcción colec- tiva y porque desarrolla los ideales consignados en los dos principios de justicia.

Lo anterior supone que, si bien es preciso preservar las condiciones e instrumentos 
consagrados constitucionalmente para hacer defensa de los derechos fundamentales, la razón pública del Estado se debe apropiar en condiciones de deliberación, al reconocer el escenario meramente político y la responsabilidad que implica para cada una de las ramas del poder público, en cuanto se deben atender como asuntos constitucionales que han de ser intervenidos por el Derecho.

Así, en el plano político aplicado al caso de Colombia, en la tabla 2 se muestran los lineamientos propuestos en las protestas populares desarrolladas durante el 2012. En esta se puede identificar que, en esencia son derechos sociales, económicos, culturales y ambientales los que fundamentan un nivel de insatisfacción generalizada sobre la política nacional. Lo interesante sobre esa dimensión parte por disposiciones de intervenciones fijadas en una fórmula mayoritaria, en las cuales las ideas del bien común se determinan como hitos problemáticos dentro del Estado (Stiglitz, 1998), como lo son el desarrollo de macro proyectos de infraestructura, afectaciones a poblaciones indígenas y prerrogativas de orden colectivo y salarial.

Esta relación entre minorías y desarrollo económico, en términos de Zoninsein (2004), tiene un impacto sobre la manera en que la administración del Estado debe considerar a quienes debe afectar para lograr el desarrollo económico colectivo. En este caso y en un primer escenario, la inmediación y la deliberación parten de determinar las condiciones de afectación menor a las a minorías. Santos (2003) iden- tifica que resguardar estas condiciones dentro del plano de la democracia implica reconocer criterios bajo los cuales, si no se genera participación, la insatisfacción y la deslegitimización de las instituciones democráticas tiende a crecer con el paso del tiempo. Es importante reconocer que una insatisfacción de orden político puede generar una crisis de legitimización de la institucionalidad frente a la cual la participación se convierte en un elemento determinante para la construcción de un modelo de desarrollo económico fijado desde la política macroeconómica del Estado. Así, se determina la relevancia de observar el caso colombiano durante el 2012 (ver tabla 2).

Asimismo, se puede observar una relación sistémica en las protestas populares del 2013 (tabla 3). Lo inquietante sobre los muestreos observados durante este año evidencia una relación entre las decisiones gubernamentales de la economía de mercado y su impacto sobre la ruralidad, como lo advierte el profesor Cano (2006), lo cual fija el impacto negativo de la apertura al mercado internacional en el desarrollo económico agrario, ligado a la producción agrícola y la extracción de minería artesanal, lo da muestras representativas sobre la deficiencia de la acción gubernamental en materia agraria. Esta disposición trae consigo una dificultad de orden práctico aparejada al olvido sistemático de la acción de gobierno que determina la necesidad de intervención sobre el espacio agrario. Si se hace una lectura progresiva sobre las condiciones de inconformidad colectiva en el sector 
Tabla 2. Protestas durante el 2012

\begin{tabular}{|c|c|c|c|c|c|c|}
\hline Fecha & Protesta & Promotores & $\begin{array}{l}\text { Alcance } \\
\text { geográfico }\end{array}$ & Repertorio & Demanda & Duración \\
\hline $\begin{array}{l}\text { Febrero } \\
2012\end{array}$ & $\begin{array}{l}\text { Protesta contra } \\
\text { megaproyectos } \\
\text { hidroeléctricos } \\
\text { y mineros }\end{array}$ & $\begin{array}{l}\text { Asociaciones } \\
\text { de pobladores } \\
\text { urbanos y se- } \\
\text { miurbanos }\end{array}$ & $\begin{array}{l}\text { Departamen- } \\
\text { tos de Huila, } \\
\text { Tolima, Quin- } \\
\text { dío, Boyacá, } \\
\text { Putumayo }\end{array}$ & $\begin{array}{l}\text { Marchas, blo- } \\
\text { queos de vías } \\
\text { principales }\end{array}$ & $\begin{array}{l}\text { No a los mega- } \\
\text { proyectos, no } \\
\text { a las transna- } \\
\text { cionales }\end{array}$ & $\begin{array}{l}\text { Varios } \\
\text { meses }\end{array}$ \\
\hline Julio 2012 & $\begin{array}{l}\text { Protestas del } \\
\text { movimiento in- } \\
\text { dígena en el } \\
\text { Norte Del Cauca }\end{array}$ & $\begin{array}{l}\text { Organizaciones } \\
\text { indígenas nasa }\end{array}$ & $\begin{array}{l}\text { Departamento } \\
\text { del Cauca }\end{array}$ & $\begin{array}{l}\text { Marchas, ex- } \\
\text { pulsión de } \\
\text { fuerza públi- } \\
\text { ca, grupos ar- } \\
\text { mados ilega- } \\
\text { les }\end{array}$ & $\begin{array}{l}\text { Respeto a la } \\
\text { autonomía te- } \\
\text { rritorial, contra } \\
\text { el racismo, por } \\
\text { la paz }\end{array}$ & $\begin{array}{l}\text { Más } \\
\text { de una } \\
\text { semana }\end{array}$ \\
\hline $\begin{array}{l}\text { Agosto } \\
2012\end{array}$ & $\begin{array}{l}\text { Protestas de } \\
\text { trabajadores de } \\
\text { multinacionales } \\
\text { electrificadoras }\end{array}$ & $\begin{array}{l}\text { Trabajadores } \\
\text { pobla d ores } \\
\text { urbanos, Union } \\
\text { Sindical Obrera }\end{array}$ & $\begin{array}{l}\text { Puerto Gaitán } \\
\text { (Meta) }\end{array}$ & $\begin{array}{l}\text { Marchas, blo- } \\
\text { queos de vías } \\
\text { principales }\end{array}$ & $\begin{array}{l}\text { Derecho a la } \\
\text { sindicalización, } \\
\text { derechos labo- } \\
\text { rales, condicio- } \\
\text { nes humanas } \\
\text { de trabajo }\end{array}$ & $\begin{array}{l}\text { Más } \\
\text { de una } \\
\text { semana }\end{array}$ \\
\hline $\begin{array}{l}\text { Octubre } \\
2012\end{array}$ & $\begin{array}{l}\text { Semana de la } \\
\text { indignación }\end{array}$ & $\begin{array}{l}\text { Congreso de } \\
\text { los pueblos, } \\
\text { marcha patrió- } \\
\text { tica nacional, } \\
\text { mesa amplia } \\
\text { nacional, estu- } \\
\text { diantes, etc. }\end{array}$ & Nacional & $\begin{array}{l}\text { Marchas, míti- } \\
\text { nes, activida- } \\
\text { des culturales }\end{array}$ & $\begin{array}{l}\text { Paz con justicia } \\
\text { social, contra } \\
\text { la desigualdad, } \\
\text { la pobreza, la } \\
\text { opresión, las } \\
\text { consecuencias } \\
\text { negativas de } \\
\text { la "locomotora } \\
\text { minero-ener- } \\
\text { gética" }\end{array}$ & $\begin{array}{l}\text { Una } \\
\text { semana }\end{array}$ \\
\hline $\begin{array}{l}\text { Diciembre } \\
2012\end{array}$ & $\begin{array}{l}\text { Paro de traba- } \\
\text { jadores de la } \\
\text { rama judicial }\end{array}$ & Asonal judicial & Nacional & $\begin{array}{l}\text { Cese de activi- } \\
\text { dades, mítines }\end{array}$ & $\begin{array}{l}\text { Reajuste sala- } \\
\text { rial }\end{array}$ & Un mes \\
\hline
\end{tabular}

Fuente: elaboración propia

agrario, este plantea de forma ínsita, una necesidad clara con respecto a la generación de producción económica en materia rural, advierte así la necesidad directa de acciones de gobierno centradas en la infraestructura y la concepción del modelo de producción macroeconómica y microeconómica del agro colombiano (Kalmanovitz, 1982).

Ahora bien, vale la pena establecer que políticamente, el desarrollo agrario no tiene una condición ligada únicamente a la concepción de democratización de la tierra y de los medios de producción, pues esto supondría una dinámica de producción macroeconómica y microeconómica de la Colombia rural que tiene un componente ampliamente político. El profesor Fajardo (2002) establece que, si no se genera una dinámica de intervención como política de Estado, cualquier acción asilada no generará efectos a largo tiempo. 
En dichos términos, plantear esto como una condición de paz presupone, de forma necesaria, una discusión sobre las dinámicas de intervención que se generan en la interpretación económica del título XII de la Constitución Política con respecto a su finalidad, en la medida en que consagra una economía social de mercado e impone una carga directa sobre los elementos normativos de intervención agraria que no supone la entrega de subsidios o medidas de bienestar, sino que implica una decisión de gobierno sobre la incorporación directa y sostenible de la economía rural enfocada en el sector primario de la economía.

Tabla 3. Protestas durante el 2013

\begin{tabular}{|c|c|c|c|c|c|c|}
\hline Fecha & Protesta & Promotores & $\begin{array}{c}\text { Alcance } \\
\text { geográfico }\end{array}$ & Repertorio & Demanda & Duración \\
\hline $\begin{array}{l}\text { Febrero- } \\
\text { marzo } \\
2013\end{array}$ & $\begin{array}{l}\text { Paro nacional } \\
\text { cafetero }\end{array}$ & $\begin{array}{l}\text { Movimiento } \\
\text { por la defensa } \\
\text { de la dignidad } \\
\text { de los caficul- } \\
\text { tores }\end{array}$ & Nacional & $\begin{array}{l}\text { M a r c h a s, } \\
\text { mítines, blo- } \\
\text { queo de vías } \\
\text { principales }\end{array}$ & $\begin{array}{l}\text { Fijación de un } \\
\text { precio remune- } \\
\text { rativo estable e } \\
\text { independiente } \\
\text { del precio in- } \\
\text { ternacional del } \\
\text { café, rechazo } \\
\text { al TLC con EE. } \\
\text { UU. }\end{array}$ & $\begin{array}{l}\text { Más } \\
\text { de una } \\
\text { semana }\end{array}$ \\
\hline Mayo 2013 & $\begin{array}{l}\text { Paro de peque- } \\
\text { ños producto- } \\
\text { res de papa }\end{array}$ & $\begin{array}{l}\text { Comité por } \\
\text { la dignidad y } \\
\text { la soberanía } \\
\text { del sector } \\
\text { papicultor de } \\
\text { Colombia }\end{array}$ & $\begin{array}{l}\text { Departamen- } \\
\text { tos de Boyacá y } \\
\text { Cundinamarca }\end{array}$ & $\begin{array}{l}\text { Marchas, blo- } \\
\text { queos de vías } \\
\text { principales }\end{array}$ & $\begin{array}{l}\text { Proteger la } \\
\text { producción } \\
\text { nacional }\end{array}$ & $\begin{array}{l}\text { Menos } \\
\text { de una } \\
\text { semana }\end{array}$ \\
\hline Junio 2013 & $\begin{array}{l}\text { Paro campesino } \\
\text { en el Catatum- } \\
\text { bo }\end{array}$ & $\begin{array}{l}\text { A socia ción } \\
\text { Campesinos } \\
\text { del Catatumbo } \\
\text { (Ascamcat) }\end{array}$ & $\begin{array}{l}\text { Región del } \\
\text { Catatumbo }\end{array}$ & $\begin{array}{l}\text { Bloqueo de } \\
\text { vías principa- } \\
\text { les }\end{array}$ & $\begin{array}{l}\text { En contra de } \\
\text { la erradicación } \\
\text { forzada de cul- } \\
\text { tivos ilícitos, } \\
\text { creación ZRC }\end{array}$ & $\begin{array}{l}\text { Cerca } \\
\text { de dos } \\
\text { meses }\end{array}$ \\
\hline Julio 2013 & $\begin{array}{l}\text { Paro de peque- } \\
\text { ños mineros } \\
\text { artesanales }\end{array}$ & $\begin{array}{l}\text { Confederación } \\
\text { Nacional de } \\
\text { Mineros de } \\
\text { Colombia (Co- } \\
\text { nalminercol) }\end{array}$ & Nacional & $\begin{array}{l}\text { Bloqueo de } \\
\text { vías principa- } \\
\text { les }\end{array}$ & $\begin{array}{l}\text { Protestas por la } \\
\text { criminalización } \\
\text { de su trabajo }\end{array}$ & $\begin{array}{l}\text { Más de } \\
\text { un mes }\end{array}$ \\
\hline $\begin{array}{l}\text { A g o s t o - } \\
\text { septiembre } \\
2013\end{array}$ & $\begin{array}{l}\text { Paro nacional } \\
\text { campesino }\end{array}$ & $\begin{array}{l}\text { Mesa nacional } \\
\text { d e unidad } \\
\text { agropecuaria } \\
\text { y popular de } \\
\text { interlocución y } \\
\text { acuerdo, coor- } \\
\text { dinador nacio- } \\
\text { nal agrario }\end{array}$ & Nacional & $\begin{array}{l}\text { Bloqueo de } \\
\text { vías principa- } \\
\text { les, marchas } \\
\text { mítines, cace- } \\
\text { rolazos }\end{array}$ & $\begin{array}{l}\text { Rechazo a los } \\
\text { acuerdos de } \\
\text { libre comercio, } \\
\text { demanda de } \\
\text { subsidios a } \\
\text { los productos } \\
\text { campesinos, } \\
\text { acceso a tierra } \\
\text { y territorio para } \\
\text { los campesinos }\end{array}$ & $\begin{array}{l}\text { Más } \\
\text { de una } \\
\text { semana }\end{array}$ \\
\hline
\end{tabular}


En el caso del 2014 (tabla 4), el rastreo muestra sistemáticamente cómo los derechos colectivos, considerados desde una perspectiva económica, plantean una dinámica sobre la disposición del Estado frente a actores que se ven afectados por su construcción económica. Esto en la medida en que la relación entre derechos colectivos y la sujeción de las cargas económicas dadas en el sector productivo y en los derechos que tienen representación económica, dan cuenta de la posición que trasciende del sector primario de la economía al sector segundario, orientado directamente a quienes son prestadores - como es el caso de los transportadores-, y en un sentido más amplio, sobre los derechos económicos de los trabajadores. Esto bajo el entendido de que, en espacios de desigualdad, la falta de acumulación y la indebida intervención generan un efecto expansivo de la crisis (Stiglitz, 2012). Esta disposición vuelve a recaer sobre los alcances con los que normativamente se regulan los asuntos inherentes a derechos sociales y cómo a su vez, estos se muestran insatisfactorios con respecto a las dinámicas prácticas alrededor de la discusión economía-Estado (Roncancio, 2013).

De igual forma, resulta inquietante observar la manera en la que estos análisis fijan su agenda sobre la política social del Estado y su financiamiento, lo cual muestra que la racionalidad propuesta por la cláusula social del Estado no implica determinar la necesidad de acciones directas sobre estas condiciones econó- micas - puesto que estas, incluso vistas desde las promesas de intervención agraria se quedarían cortas-, sino disponer medios idóneos para la financiación de la política social. Asimismo, esto involucra una discusión sobre temas inherentes al logro de la seguridad ciudadana y la pacificación armada en los territorios rurales, en los cuales es claro que la lectura de la investigación se queda corta, en la medida en que la incorporación a la vida y el contexto fuera del conflicto imponen la tarea de generar condiciones aptas de dignidad en los espacios del conflicto.

Resulta interesante para la investigación identificar como foco de las movilizaciones los territorios rurales, en los que esta lectura permite evidenciar una caracterización en dos sentidos: i) se evidencia una política de gestión que no genera de forma directa condiciones dignas de aquellos presupuestos fundamentales que se esperan de la dinámica propia del Estado: ii) la racionalidad de utilidad frente a la disposición de derechos fundamentales, cuando son sociales, económicos, culturales o ambientales, se han consolidado como meras prestaciones de las cuales el Estado se quiere desligar. En esta posición, es relevante un análisis comparativo con respecto a las condiciones pretendidas para el éxito de lo que se plantó en la mesa de conversaciones en la Habana (ver tabla 4).

Finalmente, en el último año de muestreo, la tabla 5 permite observar la tendencia que posiciona nuevamente la discusión 
Deliberación y conflicto en tiempos de hacer la paz: análisis de las protestas populares (2012-2015) en Colombia ...

Tabla 4. Protestas durante 2014

\begin{tabular}{|c|c|c|c|c|c|c|}
\hline Fecha & Protesta & Promotores & $\begin{array}{c}\text { Alcance } \\
\text { geográfico }\end{array}$ & Repertorio & Demanda & Duración \\
\hline $\begin{array}{l}\text { En e r o - } \\
\text { f e b r e r o } \\
2014\end{array}$ & $\begin{array}{l}\text { Paro de trans- } \\
\text { portadores de } \\
\text { carga }\end{array}$ & $\begin{array}{l}\text { Asociación de } \\
\text { Transportado- } \\
\text { res de Carga } \\
\text { (ATC) }\end{array}$ & Nacional & $\begin{array}{l}\text { Bloqueo de } \\
\text { vías principa- } \\
\text { les }\end{array}$ & $\begin{array}{l}\text { Estabilidad en } \\
\text { el precio del } \\
\text { combustible }\end{array}$ & $\begin{array}{l}\text { Más de } \\
\text { un mes }\end{array}$ \\
\hline $\begin{array}{l}\text { Abril-mayo } \\
\text { de } 2014\end{array}$ & $\begin{array}{l}\text { Paro nacional } \\
\text { agrario }\end{array}$ & $\begin{array}{l}\text { Organización } \\
\text { Nacional In- } \\
\text { dígena de Co- } \\
\text { lombia (ONIC), } \\
\text { Congreso de } \\
\text { los Pueblos, } \\
\text { entre muchos } \\
\text { más }\end{array}$ & Nacional & $\begin{array}{l}\text { Bloqueo a vías } \\
\text { principales, } \\
\text { marchas, míti- } \\
\text { nes, activida- } \\
\text { des culturales, } \\
\text { cacerolazos }\end{array}$ & $\begin{array}{l}\text { Ocho puntos } \\
\text { que tocan di- } \\
\text { versos aspec- } \\
\text { tos de política } \\
\text { agraria, minera } \\
\text { y territorial, } \\
\text { la solución al } \\
\text { conflicto social } \\
\text { y armado }\end{array}$ & $\begin{array}{l}\text { Dos } \\
\text { semanas }\end{array}$ \\
\hline Mayo 2014 & $\begin{array}{l}\text { Paro nacional } \\
\text { de maestros }\end{array}$ & $\begin{array}{l}\text { Fe de ra ción } \\
\text { Colombiana de } \\
\text { Trabajadores } \\
\text { de la Educa- } \\
\text { ción (Fecode) }\end{array}$ & Nacional & $\begin{array}{l}\text { Marchas, ca- } \\
\text { cerolazos }\end{array}$ & $\begin{array}{l}\text { Mejoras en } \\
\text { la salud, au- } \\
\text { mento salarial } \\
\text { y replantear } \\
\text { la evaluación } \\
\text { docente }\end{array}$ & $\begin{array}{l}\text { Una } \\
\text { semana }\end{array}$ \\
\hline Junio 2014 & $\begin{array}{l}\text { Marcha de } \\
\text { trabajadoras } \\
\text { sexuales }\end{array}$ & $\begin{array}{l}\text { Colectivo de } \\
\text { Investigación } \\
\text { Acción-Social: } \\
\text { Pluriversos, } \\
\text { Cultura y Poder }\end{array}$ & $\begin{array}{l}\text { Caldas, Mani- } \\
\text { zales }\end{array}$ & $\begin{array}{l}\text { Movilización, } \\
\text { manifestación } \\
\text { en plaza pú- } \\
\text { blica }\end{array}$ & $\begin{array}{l}\text { Respeto, segu- } \\
\text { ridad }\end{array}$ & $\begin{array}{l}\text { Menos } \\
\text { de una } \\
\text { semana }\end{array}$ \\
\hline
\end{tabular}

Fuente: elaboración propia

sobre los derechos considerados como sociales, económicos, culturales y ambientales, en ella se confirma la tendencia sobre el posicionamiento descrito para los años precedentes.

Ahora bien, todas las protestas contempladas en la muestra han tenido un efecto e impacto muy importante en la sociedad. McAdam y Tarrow (2004, p. 5) conciben la contienda política como:

[...] la interacción episódica, pública y colectiva entre los reivindicadores y sus objetos cuando: (a) al menos un gobierno es uno de los reivindicadores y (b) las reivindicaciones, en caso de ser satisfechas, afectarían a los intereses de al menos uno de los reivindicadores.

A la luz de lo que pretende transmitir el Acuerdo de Paz entre las FARC-EP y el Estado colombiano, esto genera un efecto inmediato sobre la disposición de una agenda pública que plantea cómo el Estado va a atender la concepción de los derechos sociales. Esto ineludiblemente escapa a la decisión judicial, en tanto no puede condicionarse sin la planeación efectiva de los recursos económicos que plantean la sostenibilidad de los derechos sociales. 
Tabla 5. Protestas durante el 2015

\begin{tabular}{|c|c|c|c|c|c|c|}
\hline Fecha & Protesta & Promotores & $\begin{array}{l}\text { Alcance } \\
\text { geográfico }\end{array}$ & Repertorio & Demanda & Duración \\
\hline $\begin{array}{l}\text { Febrero } \\
2015\end{array}$ & $\begin{array}{l}\text { Resistencia in- } \\
\text { dígena }\end{array}$ & $\begin{array}{l}\text { Organizacio- } \\
\text { nes indígenas }\end{array}$ & Cauca & $\begin{array}{l}\text { Movilización, } \\
\text { actos cultura- } \\
\text { les }\end{array}$ & $\begin{array}{l}\text { Rechazo a la } \\
\text { violencia en } \\
\text { sus territorios }\end{array}$ & $\begin{array}{l}\text { Menos } \\
\text { de una } \\
\text { semana }\end{array}$ \\
\hline $\begin{array}{l}\text { Marzo-abril } \\
2015\end{array}$ & $\begin{array}{l}\text { Marcha por las } \\
\text { víctimas }\end{array}$ & $\begin{array}{l}\text { Gobierno } \mathrm{Na}- \\
\text { cional, Alcaldía } \\
\text { de Bogotá, Bo- } \\
\text { gotá Humana }\end{array}$ & Nacional & $\begin{array}{l}\text { Movilización, } \\
\text { silencio por } \\
\text { las víctimas }\end{array}$ & $\begin{array}{l}\text { Derecho a la } \\
\text { paz, respaldo a } \\
\text { los acuerdos }\end{array}$ & $\begin{array}{l}\text { Menos } \\
\text { de una } \\
\text { semana }\end{array}$ \\
\hline $\begin{array}{l}\text { Marzo } \\
2015\end{array}$ & $\begin{array}{l}\text { Paro de trans- } \\
\text { portadores de } \\
\text { carga }\end{array}$ & $\begin{array}{l}\text { Asociación de } \\
\text { Transportado- } \\
\text { res de Carga } \\
\text { (ATC) }\end{array}$ & Nacional & $\begin{array}{l}\text { Bloqueo de } \\
\text { vías princi- } \\
\text { pales }\end{array}$ & $\begin{array}{l}\text { Reajuste en } \\
\text { tabla de fletes, } \\
\text { rebaja al precio } \\
\text { del combus- } \\
\text { tible }\end{array}$ & $\begin{array}{l}\text { Más de } \\
\text { un mes }\end{array}$ \\
\hline $\begin{array}{l}\text { Septiembre } \\
2015\end{array}$ & $\begin{array}{l}\text { Paro estudiantil } \\
\text { de Cartagena }\end{array}$ & $\begin{array}{l}\text { Estudiantes de } \\
\text { la Universidad } \\
\text { de Cartagena }\end{array}$ & $\begin{array}{l}\text { Bolívar, Carta- } \\
\text { gena }\end{array}$ & $\begin{array}{l}\text { Movilización, } \\
\text { cacerolazos, } \\
\text { carteles }\end{array}$ & $\begin{array}{l}\text { Mejora de do- } \\
\text { centes e insta- } \\
\text { laciones }\end{array}$ & Un mes \\
\hline $\begin{array}{l}\text { Diciembre } \\
2015\end{array}$ & $\begin{array}{l}\text { Paro de con- } \\
\text { ductores de au- } \\
\text { tobuses }\end{array}$ & Manifestantes & $\begin{array}{l}\text { Bolívar, Carta- } \\
\text { gena }\end{array}$ & $\begin{array}{l}\text { Bloqueos de } \\
\text { vías de la ciu- } \\
\text { dad }\end{array}$ & 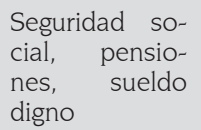 & $\begin{array}{l}\text { Más } \\
\text { de una } \\
\text { semana }\end{array}$ \\
\hline
\end{tabular}

Fuente: elaboración propia

Esto conduce a lo que Boaventura Santos (2001, p. 177) expresa de la siguiente manera: "la difusión social de la producción contribuyó a desenmascarar nuevas formas de opresión y que el aislamiento político del movimiento obrero facilitó el surgimiento de nuevos sujetos sociales y de nuevas prácticas de movilización social". Esto se evidencia claramente en el contexto colombiano al denotar que siempre son los mismos grupos los que se sienten inconformes y marginados, grupos poblacionales que son esenciales para el crecimiento y desarrollo de toda sociedad.

Al respecto, este estudio advierte sobre la importancia de que las demandas estructuradas en el plano de las protestas populares sean consideradas condiciones circunstanciales del proceso de imple- mentación del Acuerdo de Paz. En suma, estos esfuerzos, además de generar un espacio de legitimación, tienen un efecto de construcción de los derechos fundamentales de quienes han sido afectados por el conflicto, se da así por sentado que el escenario de la implementación del acuerdo se convierte en un escenario valioso en la medida en que reivindica la Constitución y el papel institucional del Estado.

\section{CONCLUSIONES}

A partir del análisis propuesto, se hace evidente que para determinar cuál es el escenario en el que se debe implementar el denominado posconflicto, se deben tener en cuenta unas cuestiones implícitas que se diagnostican a través de las interacciones que se evidencian en cada 
una de las protestas populares, las cuales, más allá de su consideración coyuntural, permiten identificar una insatisfacción continua sobre la forma en la que el Estado ha presupuestado desarrollar su política social, conforme establece la Constitución.

De tal manera, esta investigación pretende dar cuenta de que es muy poco probable que las acciones del posconflicto o posacuerdo, dependiendo la posición teórica que se plantee, podrán tener éxito si el Estado, como institución, no dispone una línea clara y directa sobre cómo gestiona la política social. Se entiende con ello que la generación de condiciones y medios determinan cómo económicamente se crean dichas condiciones de sostenibilidad, especialmente en los territorios rurales y de conflicto, puesto que la generación de condiciones productivas no puede estar atada a consideraciones de bienestar dadas en subsidios o prebendas, pues condicionan su éxito a la voluntad política y a la disponibilidad presupuestal.

En ese sentido, el Estado debe plantear que si se circunscribe a una política de financiación de la política social, esta implica el reconocimiento de una ciudadanía activa que haga control sobre las decisiones del Estado y, de forma consecuente, a la construcción de una política tributaria y fiscal que involucre a todos los actores, desde la ciudadanía hasta el empresariado, teniendo en cuenta la equiparación de cargas y priorizando la financiación de los derechos sociales. Esto puesto que, conforme a la propuesta de Holmes y Sunstein (2015), los derechos no tienen sentido si se quedan en un plano meramente positivo.

Con todo, las protestas populares evidencian un malestar generalizado sobre la cuestión de los derechos sociales, económicos, culturales y ambientales en la medida que su consagración dogmática constitucional genera una expectativa de exigibilidad que no se encuentra satisfecha. Se plantea entonces la adecuación de la estructura del Estado para garantizar la financiación estatal con la corresponsabilidad de los actores, o la resignificación de los alcances de progresividad que se entienden como exigibles. No obstante, su valor es importantísimo, pues proponen una ruta de conceptualización alrededor de aquello que la ciudadanía debe reclamar y construir y de lo que la institucionalidad debe desarrollar en la agenda de gobierno. Finalmente, se puede afirmar que los derechos fundamentales se construyen en el plano político, pero solo surgen como derechos fundamentales en la medida en que son positivados e interpretados conforme a los lineamientos que se han construido alrededor de la Constitución.

\section{REFERENCIAS}

Alterio, A., y Niembro, R. (2018, octubre 8). La democracia y sus procesos. Nexos. El juego de la Suprema Corte. Recuperado de https:// eljuegodelacorte.nexos.com.mx/?author $\underline{\text { name }=\text { micaela-alterio }}$

Arango, R. (2001, junio). La justiciabilidad de los derechos sociales fundamentales. Revista de Derecho Público, (12), 185-212. Recuperado 
de https://derechopublico.uniandes.edu. co/components/com revista/archivos/ derechopub/pub202.pdf

Baños, J. (2006). Teorías de la democracia: debates actuales. Andamios, 2(4), 35-58. Recuperado de http://www.redalyc.org/ articulo.oa?id=62820402

Castro, E., Vélez, J., y Madrigal, M. (2018). Desplazamiento forzado, reasentamiento y cambio climático. Medellín: Sello Editorial Universidad de Medellín.

Cano, C. (2006). TLC y sector agrario. Revista Javeriana, (729), 32-39.

Dueñas, O. (2011). Lecciones de hermenéutica jurídica (6 $6^{\circ}$ ed.). Bogotá, Colombia: Universidad del Rosario.

Duque, C. (2014). La ética del discurso ante el desafío del (neo) populismo en Latinoamérica y la radicalización de la democracia. Revista CS, (13), 47-84. Recuperado de https://www. icesi.edu.co/revistas/index.php/revista_cs/ article/view/1821

Durán, D. (2011). Entre el republicanismo y el constitucionalismo popular ¿Cómo potenciar la participación democrática en la construcción de la política pública y constitucional del bien común? Vniversitas, 60(123), 169-202. Recuperado de http://revistas.javeriana.edu. co/index.php/vnijuri/article/view/14315

Fajardo, D. (2002). Para sembrar la paz, hay que aflojar la tierra: comunidades, tierras y territorios en la construcción de un país. Bogotá, Colombia: Universidad Nacional de Colombia.

Ferrer, N. (2010). El acceso a la Justicia como elemento indispensable del ejercicio de la ciudadanía femenina. Opinión Jurídica, 9(17), 113-126. Recuperado de https://dialnet. unirioja.es/descarga/articulo/3294160.pdf

Ferrer, N. (2017). Los nuevos movimientos sociales y las ciudadanías emergentes: reflexiones desde el concepto de democracia radical y el movimiento LGBTI en Colombia. Revista Estudios Socio-Jurídicos, 19(1), 43-62. Recuperado de https://revistas.urosario.edu. $\mathrm{co} / \mathrm{xml} / 733 / 73348834003 / \mathrm{html} /$ index.html

Gargarella, R. (2007). El nacimiento del constitucionalismo popular. Sobre The People Themselves, de Larry Kramer. Jura Gentium: Revista de Filosofía del Derecho Internacional $y$ de la Política Global, 1-7. Recuperado de https://www.juragentium.org/topics/latina/ es/gargarel.pdf

Habermas, J. (1994, diciembre). Three Normative Models of Democracy. Constellations, 1(1), 1-10. Recuperado de https://pdfs.semanticscholar.org/ec92/504aac4db909079a9038e2f0 f4501d668393.pdf

Holmes, S., y Sunstein, C. (2015). El costo de los derechos: ¿por qué la libertad depende de los impuestos? ( $3^{\circ}$ ed.). Buenos Aires: Siglo Veintiuno Editores.

Kalmanovitz, S. (1982). El desarrollo de la agricultura en Colombia. Bogotá: Carlos Valencia Editores.

Kramer, L. (2004). The people themselves: popular constitutionalism and judicial review. Oxford, Reino Unido: Oxford Press.

Kymlicka, W. (1995). Multicultural Citizenship: a liberal theory of minority rights. Oxford, Reino Unido: Claredon Press-Oxford.

Malagón, L. (2014). Entre el constitucionalismo democrático y el constitucionalismo popular: Análisis de la jurisprudencia constitucional en la defensa de los derechos de la población LGBTI en Colombia (Tesis de Maestría en Derecho - Profundización en Derecho Constitucional). Universidad Nacional de Colombia. Bogotá, Colombia: Recuperado de http://bdigital.unal.edu. co/40029/1/6701030.2014.pdf

McAdam, D., y Tarrow, S. (2004). Scale Shift In Transnational Contention. En D. Della Porta, 
y S. Tarrow, Transnational protest and global activism (p. 304). Unites States: Rowman \& Littlefield Publishers.

Niembro, R. (2013). Una mirada al constitucionalismo popular. Isonomía: Revista de Teoría y Filosofía del Derecho, (38), 191-224. Recuperado de http://www.redalyc.org/articulo. oa?id $=363633426007$

Moreno, V., Roncancio, A., Restrepo, J., y Carvajal, S. (2017). Línea jurisprudencial constitucional sobre el cambio del modelo jurídico-político familiar en Colombia (1996-2016). En J. D. Restrepo Yepes, R. Betancur Durango y V. Moreno Mosquera (Comps.), Auditorio constitucional: discusión y reflexión sobre algunos temas de investigación jurídica (pp. 129-202). Envigado: Fondo Editorial IUE.

Moreno, V., Roncancio, A., Lopera, D., y Carvajal, S. (2018). Población LGBTI como víctima invisible en el conflicto armado colombiano: recomendaciones para el posconflicto. En J. D. Restrepo Yepes, R. Betancur Durango y V. Moreno Mosquera (Comps.), Auditorio constitucional resultados y avances en investigación jurídica (pp. 51-76). Envigado: Fondo Editorial IUE

Pabón Giraldo, L. D., Bustamante Rúa, M. M., y Toro Garzón, L. O. (2017). La legitimidad de la justicia transicional en Colombia: una mirada procesal desde del derecho internacional. En C. Agudelo Mejía, L. D. Pabón Giraldo, L. O. Toro Garzón, M. M. Bustamante Rúa y O. Vargas Vélez (Coords.), Justicia transicional (pp. 149-182). Medellín: Sello editorial Universidad de Medellín.

Post, R., y Siegel, R. (2013). Constitucionalismo democrático: por una reconciliación entre Constitución y pueblo. Buenos Aires: Siglo XXI Editores.

Post. R. y Siegel, R. (2017). La ira de Roe: el constitucionalismo democrático y el contraataque conservador (backlash). UNA: revista de Dereho, 2, 1-81. Recuperado de https:// una.uniandes.edu.co/images/pdfedicion2/
Traducciones/Post- -Siegel-2017- - -UNARevista-de-Derecho.pdf

Przeworski, A. (2010). ¿Qué esperar de la democracia? Límites y posibilidades del autogobierno. Buenos Aires: Siglo Veintiuno Editores.

Rawls, J. (2004). El liberalismo político. (A. Doménech., Trad.) Barcelona: Crítica.

Restrepo, J. (2012). Aproximación a la idea de razón publica según John Rawls. Pensamiento y Poder, 1(10), 59-71. Recuperado de http:// fer.uniremington.edu.co/ojs/index.php/PYP/ article/view/73/83

Restrepo, J. (2018). Estructura constitucional del Estado colombiano ( $2^{\circ}$ ed.). Medellín, Colombia: Sello Editorial Universidad de Medellín.

Restrepo-Yepes, O. C., Restrepo-Ruiz, A., MolinaBetancur, C. M., Molina-Saldarriaga, C. A., Giraldo-Ramírez, D. P., Carrasquilla-Salazar, D. A., Restrepo Tamayo, J.., Restrepo Yepes, J. D., Rivera Ríos, J., Bedoya Taborda, L. F., Bocanument Arbeláez, M., Zapata Ospina, M., Rojas Betancur, M. A., Betancourt Durango, R. A. y Moreno Mosquera, V. J. (2017). Seguridad alimentaria y derecho a la alimentación en escenarios de posconflicto. Análisis, para determinar estándares de política pública, del acuerdo "Política de desarrollo agrario integral", logrado entre Gobierno nacional de Colombia y las FARCEP. Medellín: Sello Editorial Universidad de Medellín, Editorial UPB, Fondo Editorial IUE, Fondo Editorial Unisabaneta.

Roncancio, A. (2013). Más allá de la justiciabilidad de los derechos sociales: neoliberalismo y gobierno en Colombia. Nuevo Derecho, 9(13), 79-88.

Roncancio, A., Hurtado, D., y Vargas D. (2018). Servicios públicos y justiciabilidad como garantía de los derechos sociales en Colombia. En C. Hernández Aguirre et al. (Eds.), Reflexiones sobre la constitución mexicana a partir de controversias relevantes en materia de derechos 
humanos. (pp. 205-250). Ensenada-Yucatán: Editorial Universidad Autónoma de Baja California, Universidad Autónoma de Yucatán, Editorial Res Publica.

Roncancio, A. y Londoño, D. (2015). Proceso de paz colombiano en prensa y revistas: un análisis desde la aproximación histórica discursiva y la argumentación pragmadialéctica. Revista Virtual Universidad Católica del Norte, (44), 81-101.

Roncancio, A., Moreno, V. y Hurtado, D. (2016). El papel del defensor de derechos humanos como parresiasta: desafíos para la construcción de paz en el proceso de finalización del conflicto armado en Colombia. Revista Via Iuris, (21),165-181.

Roncancio, H. y Roncancio, A. (2014). Acción de inconstitucionalidad: de la supremacía de la constitución. En P. Garcés Vásquez (Ed.), Acciones constitucionales: una aproximación a la eficacia y efectividad de los derechos (pp.131-172). Envigado, Antioquia: Fondo Editorial IUE.

Santos, B. (2001). Los nuevos movimientos sociales. OSAL (5), 177-188. Recuperado de http://www.boaventuradesousasantos.

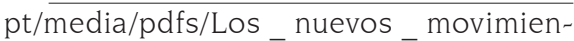
tos_sociales OSAL2001.pdf

Santos, B. (2003). Crítica de la razón indolente: contra el desperdicio de la experiencia. Para un nuevo sentido común: la ciencia, el derecho y la política en la transición paradigmática (vol. I). Bilbao: Descleé de Brouwer. Recuperado de http://biblioteca.clacso.
edu.ar/Argentina/iigg-uba/20161110024742/ Critica.pdf

Serna, P. (2008, noviembre). Democracia radical y ciudadanía. Eidos: Revista de Filosofía de la Universidad del Norte, (9), 272-280. Recuperado de http://www.redalyc.org/articulo. oa?id $=85416265010$

Stiglitz, J. (1998). Más instrumentos y metas más amplias para el desarrollo. Hacia el consenso post-Washington. Desarrollo económico, 38(151), 691-722. Recuperado de https://www.jstor. org/stable/3467160?seq=1\#page _scan tab_contents

Stiglitz, J. (2012). El precio de la desigualdad: el 1\% de población tiene lo que el 99\% necesita. Madrid: Taurus.

Tobón, M., y Mendieta, D. (2017). Los estados de excepción en el régimen constitucional colombiano. Revista Opinión Jurídica, 16(31).67-88.

Vidiella, G. (2013). Democracia: ¿razones o pasiones? Tópicos (25), 63-80. Recuperado de http:// www.redalyc.org/pdf/288/28829922004.pdf

Young, I. (2002). Inclusion and Democracy. Reino Unido: Oxford University Press.

Zoninsein, J. (2004). Minorias étnicas e a economia política do desenvolvimento. Revista económica, 6(1), 105-121. Recuperado de http://www.revistaeconomica.uff.br/index. php/revistaeconomica/article/view/197 $/ 170$ 